\title{
CAPACITAÇĀO DO PROFISSIONAL DE SAÚDE NO ÂMBITO DA FORMAÇÃO E DA EDUCAÇÃO CONTINUADA*
}

\author{
Dra Paulina Kurcgant** \\ Valéria Castilho*** \\ Dra Maria Madalena Januário Leite****
}

KURCGANT, P. et al. Capacitaçảo do profissional de saùde no àmbitu da formaçào e da educação continuada. Rev.Esc.Enf.USP,v.28, n.3, p.251-6, dez. 1994.

Este trabalho tem como objetivo analisar os documentos legais que tratam de temáticas referentes ao modelo assistencial de saude e à formação e capacitação de recursos humanos nessa área. Dessa forma foram analisadas a Constituição da República Federativa do Brasil, o Relatório da IX Conferència Nacional de Saúde e 0 Projeto de Diretrizes e Bases da Educação Nacional. Nesse referencial estão embutidas as bases prospectivas para a concretização de estratégias educativas e gerenciais democraticas e participativas; de ideologias permeadas pelo respeito à dignidade humana; de propostas de trabalho condizentes com o bem-estar do homem; de progra. mas que integrem o ensino e a pratica profissional e, finalmente, de propostas que, efetivamente, promovam, recuperem e reabilitem a saude de uma coletividade.

UNITERMOS: Capacitação Profissional. Formação Profissional.

As perspectivas da capacitação do profissional de saúde, tanto no que se refere à formação profissional básica como a continuidade dessa capacitação, serão visualizados, no decorrer deste estudo, segundo a realidade atual, as tendências sociais e administrativas e os referenciais de documentos legais que têm direcionado o ensino e a prática desses profissionais.

A descrição da realidade vivenciada no ensino e na prática, pelo pessoal de saúde, tem mostrado que o termo "capacitação" é entendido como o preparo do indivíduo para o desempenho de suas atividades profissionais.

Para a efetiva compreensão do significado do termo, há necessidade de se entender o ambiente onde a capacitação ocorre e os fatores que nas organizaçōes hospitalares, têm interferido, no seu desenvolvimento.

\footnotetext{
- Trabalho apresentado no Encontro de Integraçăo multiprofissional na área hospitalar promovido pelo Hospital das Clínicas da Faculdade de Medicina da USP.

* Professor Titular da Escola de Enfermagem da USP.

*** Assistente da EEUSP e doutoranda do Programa Interunidades de Pós-liraduaçào (EEUSP.EERP.USP).

**** Professor Doutor da EEUSP.
} 
Nessa realidade, os hospitais têm-se caracterizado como ambiente cuja cultura é impregnada de autoritarismo, burocracia e alienação de sua força de trabalho, preocupados em manter os "status quo" ou seja, manutençāo das regras determinadas pelo grupo de poder. Esses ambientes concorrem para pouca ou nenhuma possibilidade de mudança.

Do ponto de vista da gestão dos recursos humanos, não tem havido grande preocupação com as pessoas, isto é, com a sua realização intelectual, sriativa e social. O trabalho é organizado segundo métodos e processos repetitivos e normatizados, o que oferece pouca ou nenhuma possibilidade ao trabalhador para usar sua energia criadora ou tomar decisões em que estaria sapacitado a fazê-lo.

Conseqüentemente a esses fatores do contexto cultural dos hospitais, a :apacitação dos trabalhadores dá-se de forma automática, massificada, pouco Jreocupada com a realização das pessoas como indivíduo, e voltada apenas Jara 0 atendimento das expectativas do grupo dominante da organização.

Em decorrência dessa política de gerenciamento de recursos humanos, Im tais ambientes são freqüentemente encontradas pessoas pouco reflexivas : críticas, com dificuldade em operar mudanças no seu processo de trabalho, :om pouco interesse no próprio desenvolvimento profissional e sem o compronisso com os resultados do seu trabalho.

Um fator que tem corroborado para esse quadro é o processo educacional rrasileiro que, devido à baixa qualidade de ensino de todos os níveis, forma rrofissionais sem consciência crítica e reflexiva de sua realidade, e com déficit m sua capacitaçāo técnica.

Além disso, outros fatores externos ao ambiente hospitalar, como desenolvimento tecnológico, movimentos sociais e quadro econômico do país, têm nostrado a necessidade de mudanças profundas tanto na estrutura como na ultura e postura ética das organizaçōes. Tais mudanças visam provocar rodificações nas premissas e políticas gerenciais de recursos humanos.

Ao nivel individual, o rápido desenvolvimento tecnológico tem gerado a mpossibilidade do profissional dominar todo o conhecimento de sua área, o ue exige dele um esforço constante do "aprender-desaprender-aprender ovamente", devido à rapidez das transformaçōes ocasionadas por esse avano.

Com a transformação tecnológica o trabalho rotineiro e repetitivo tem ido modificado pelos computadores, e o trabalho intelectual tem crescido celeradamente, pois, além de saber manipular a tecnologia, o trabalhador recisa reintegrar no seu processo de trabalho o saber, resolvendo problemas aplicando soluçōes para manter as máquinas funcionando (LUCENA)

No campo social há a procura da satisfação humana, onde há um desejo - auto-realização pessoal e profissional no trabalho, e uma busca pela telhoria da qualidade de vida. Isso tem se refletido nos movimentos sociais que tem gerado leis que enfatizam o processo participativo e o respeito à gnidade humana no âmbito da educação e do trabalho.

Além disso, pelo processo de democratização, no qual as pessoas têm aior liberdade de se expressar, e pelas tendências de mercado, devido às 
inúmeras opções de escolha, o consumidor tem-se tornado mais exigente e seletivo, buscando a qualidade dos produtos e serviços. Em consequência, as organizações terão de se estruturar para atenderem a um novo perfil de consumidor, correndo o risco de não sobreviverem a um mercado cada vez mais competitivo e exigente.

A pressão desses fatores tem demonstrado a necessidade das organizaf̧ões baseadas em esquemas rígidos, racionais e burocráticos de criarem um clima que propicie o pleno desenvolvimento das pessoas, traduzido por alto nivel de competência profissional, auto-realização pessoal e compromisso com os resultados organizacionais e sociais.

Para tanto, a capacitação desenvolvida dentro das organizações hospitalares não pode ser vista como algo que objetiva única e exclusivamente o desenvolvimento de um conjunto de aulas, cursos e palestras voltadas apenas para o treinamento técnico, para a satisfação de alguns requisitos da organização.

Devem ser adotadas políticas e práticas de gestão de recursos humanos que contemplem a complexidade e a natureza mutativa dos ambientes externos e internos da organização, os avanços da tecnologia; e que ainda enfrente o processo de alienação do trabalhador e que nele acredite valorizando a sua contribuição para o sucesso da organização (LUCENA) 4 .

Para tanto, faz-se necessário uma transformação no processo decisório das organizaçōes em relação à administração dos recursos humanos, ou seja, que ela esteja mais voltada para resolver problemas através de ações pró-ativas, e que todas as pessoas, em todos os níveis da estrutura organizacional, considerem que essas açōes são resultantes da sinergia existente entre as forças geradas por fatores tanto externos como internos da organização. As forças internas resultam da interação e interdependência dos fatores pessoais e organizacionais.

Porém, a percepção dos fatores externos à organização é o que possibilita a real inserção das propostas internas, que se referem à capacitação dos recursos humanos no contexto global da assistência à saúde.

Assim, quanto aos dispositivos legais, sem dúvida é na Nova Constituição da República do Brasil, promulgada em 1988, que se encontra explicada a razão maior do ser e do atuar dos profissionais de saúde. Nela estão assegurados o Estado Democrático de Direito de todo cidadão brasileiro, tendo, como âncora, o respeito à dignidade humana.

O artigo $6^{9}$, incluso no título que trata dos Direitos e Garantias Fundamentais de todo Cidadão Brasileiro, preconiza como direitos sociais: a educação, a saúde, o trabalho, o lazer, a segurança, a previdência social, a proteção à maternidade e a infância e a assistência aos desamparados.

No que se refere, especificamente, à continuidade da capacitação do pessoal, as instituiçōes e as pessoas que assumem a missão de prepará-los, é encontrado no artigo 200 da Constituição, a explicitação de suas responsabilidades nos dizeres:"Compete ao Sistema Único de Saúde (SUS), ordenar a formação de recursos humanos na área de saúde". 
Outras informações preciosas a serem analisadas, quando pretendemos conhecer os pontos focais que obrigatoriamente terão de ser considerados nas propostas sobre desenvolvimento de recursos humanos, referem-se às considerações e conclusões da IX Conferência Nacional de Saúde realizada em Brasília em agosto de 1992.

A importância da realização desse evento não reside apenas nos subsidios que proporcionam a efetivação das açōes de saúde, mas também ao fato de ter tido no decorrer de todo o processo a efetiva participação da população brasileira, de profissionais de saúde e de representantes do governo.

É nesse documento, baseado na nova Constituição Brasileira, que ficam assegurados os direitos à saúde e à criação de um sistema de saúde democrático e comprometido com as necessidades da sociedade. Assim, a IX Conferência acima citada, faz incursões nas temáticas referentes ao modelo assistencial e à capacitação e aprimoramento de recursos humanos para a saúde.

Esta aí clarificada a direçāo a ser seguida para o ensino e a prática desses profissionais: as propostas assistenciais deverão ser priorizadas de acordo com as necessidades identificadas junto à população; o novo modelo assistencial deve ter base epidemiológica, garantindo à população: acesso universal em todos os níveis da assistência, eqüidade, resolutividade, integralidade da atenção em um sistema de complexidade crescente. Nesse documento, o hospital é caracterizado como um serviço de referência para o desenvolvimento de açōes de saúde complexas, que exigem recursos humanos e materiais adequados e práticas diferenciadas.

Em tais instituições, os modelos assistenciais não devem ser limitados à assistência individual e curativa, mas devem contemplar também ações programáticas que visualizem grupos, bem como ações de educação em saúde. Devem ser estabelecidos critérios de avaliação com base na efíciência das ações e na qualidade dos resultados. Outro ponto importante enfocado no documento, é o que considera a necessidade de serem destinados recursos para a pesquisa científica e para a utilização de novas tecnologias nas instituições hospitalares.

$\dot{E}$ ainda na nova proposta, quando trata de recursos humanos, onde está explicita a necessidade de ser adotada uma política nacional de recursos humanos, que contemple a criação de quadros de profissionais como a implantação de um plano de carreira; que contemple ainda a qualificação e/ou formação permanente de pessoal, de forma a permitir a evolução do trabalhador na carreira; a revisão dos currículos profissionais, que devem ser adequados as realidades sócio-epidemiológicas, bem como a garantia de condições de trabalho favoráveis a todos os profissionais de saúde. O relatório da Conferência citada considera necessário que seja assegurada, em nível nacional, uma política de formação/capacitação de recursos humanos, que se articule com os órgãos formadores, e que, no nível local, garanta uma política de desenvolvimento da formação e capacitação de pessoal, a fim de possibilitar uma atuação ética de elevado nível técnico. Considera, ainda, a necessidade de recursos financeiros para capacitação do pessoal, bem como a garantia de uma assistência à população dada por equipe multidisciplinar. 
Quanto ao aspecto legal, as considerações da nova Constituição e da IX Conferência Nacional de Saúde são dois importantes caminhos que orientam a capacitação dos recursos humanos em saúde quando esses recursos constituem investimento. As instituições de saúde, em suas propostas de aprimoramento de pessoal, não poderão desconhecer ou omitir o conteúdo normativo desses documentos. A negação desses aspectos nos programas de desenvolvimento de pessoal pode revelar a intencionalidade, nessas instituições, de se adotar o processo educativo como instrumento de poder e de interesses particulares, contrários, muitas vezes, aos interesses do coletivo.

Quanto à educação, visualizada como processo ativo da formação profissional, a IX Conferência considera necessário o estabelecimento de critérios para a formação de profissionais de nível técnico e de nível superior na área da saúde. Tais critérios, definidos pelo SUS, devem ser considerados pelo Conselho Federal de Educação - MEC, para a abertura de novos cursos, e para a aprovação do currículo dos cursos já em funcionamento. É ainda neste documento preconizado que a educação para a formação profissional deve "garantir a formação de profissionais" com visão integral, comprometimento social e formação geral; ainda considerando a necessidade de ser efetivada a avaliação do ensino em saúde.

Sem dúvida esses referenciais embasam e direcionam os novos caminhos para a formação e a atuação dos profissionais de saúde.

Outro referencial teórico-metodológico que deve ser considerado na formação desse pessoal é o atual projeto da "Lei de Diretrizes e Bases da Educação Nacional". Neste documento, o capítulo que trata dos fins da educação a indica como um instrumento da sociedade para o exercício da cidadania e visualiza o trabalho como parte de riqueza, dignidade e bem estar universal. Assim, a missão da educação é o pleno desenvolvimento do ser humano, por meio da formação de cidadãos capazes de compreenderem criticamente a realidade social pelo desenvolvimento de valores éticos e do aprendizado participativo. Considera, ainda, como missão da educação, o preparo do cidadão para a compreensão e o exercício do trabalho mediante acesso à cultura e ao conhecimento científico e tecnológico. Especificamente na formação de nível superior, orienta para a integração do ensino com a pesquisa e as atividades de extensão de serviços à comunidade. Orienta, também, a obtenção da capacitação profissional pelo exercício da reflexão crítica e a participação na produção, sistematização e superação do saber.

Com o objetivo de propiciar uma formação profissional de qualidade, esse documento promove a valorização da competência e a garantia das condições de trabalho. Propõe a integração entre a educação escolarizada formal e as educativas produzidas fora dos sistemas de ensino; a flexibilidade para o reconhecimento de experiências extra-escolares e o processo de valorização institucional.

É nesse referencial teórico que estão embutidas as bases prospectivas para a concretização de estratégias educativas e gerenciais democráticas e participativas; de ideologias permeadas pelo respeito à dignidade humana; de condiçōes de trabalho condizentes com o estar do homem; de propostas que 
integrem o ensino e a prática profissional e, finalmente, de propostas que, efetivamente, promovam, recuperem e reabilitem a saúde de uma coletividade.

KURCGANT, P. et al. Capability of health professional people under the scope of formal and continuous education. Rev.Esc.Enf.USP,v.28, n.3, p.251-6, dec. 1994.

This paper has as objective the analysis of legal documents that cover the subject of assistance health models and the formal and continuous education human resources in this area. This way, an analysis has been made of the Brazilian Federative Republic Constitution, the Report of the $9^{\text {th }}$ National Health Conference and the Project for Directions and Basis of the National Education. On these references are embedded the prospective basis for the materialization of education and managerial strategies, both democratic as participative, of ideologies oriented to the respect for the humam being; of working propositions compatible whit makind welfare; of programs that integrate the teaching process and the professional practice and last, the proposals that effectively promote, recover and enable the health of a collectivity.

UNITERMS: Professional Capability. Formal Education.

\section{REFERÊNCIAS BIBLIOGRÁFICAS}

1. BRASIL. Constituição, 1988. Constituição da República Federativa do Brasil, 1988. São Paulo, IMESP, 1988.

2. BRASIL. Ministério da Educação e Cultura. Lei de diretrizes e bases da educaçào nacional. Brasilia, 1990/mimeografado/.

3.BRASIL. Ministério da Saude. Relatório final da $9^{\bullet}$ Conferência Nacional de Saúde. Brasilia, 1992./mimeografado/.

4. LUCENA, M.D. da S. Planejamento de recursos humanos. São Paulo, Atlas, 1991. 